\title{
Board 85: Integrated Engineering Leadership Initiative for Teaching Excel- lence (iELITE) Year Two: Assessment of Intermediate-Term Outcome for Graduate Teaching Assistant Training
}

\author{
Dr. Yuting W. Chen, University of Illinois at Urbana-Champaign
}

Dr. Yuting W. Chen received the B.S. degree from University of Illinois - Urbana Champaign in 2007, and the M.S. and Ph.D. degrees from Rensselaer Polytechnic Institute in 2009 and 2011, all in Electrical Engineering. Prior to joining the Department of Electrical and Computer Engineering at University of Illinois at Urbana-Champaign as a faculty in 2015, she worked at IBM Systems Group in Poughkeepsie, NY in z Systems Firmware Development. Her current interests include recruitment and retention of women and under-represented students in STEM, integrative training for graduate teaching assistants, and curriculum innovation for introductory programming courses.

\section{Hyun Hannah Choi, University of Illinois, Urbana-Champaign}

Hannah Choi is an assistant director of assessment and curriculum design at the Center for Innovation in Teaching and Learning. She collaborates with faculty to conduct research, program evaluations, and learning outcomes assessments pertinent to innovative curriculum designs and educational technologies. She is responsible for fostering continuous improvement in teaching, student experiences, and educational programs through the use of development and learning theories. Her areas of focus include, among others, experiential learning, internationalizing curriculum, online learning, and educational technology innovations.

\section{Dr. Blake Everett Johnson, University of Illinois at Urbana-Champaign}

Dr. Blake Everett Johnson is a lecturer and instructional laboratory manager in the Department of Mechanical Science and Engineering at the University of Illinois at Urbana-Champaign. His research interests include experimental fluid mechanics, measurement science, and engineering education. He oversees undergraduate laboratories in fluid mechanics, fluid dynamics, and heat transfer. Pedagogically, Dr. Johnson employs active learning, inquiry-based laboratory instruction, and any initiative that empowers students to do hands-on learning. Additional service interests include teaching and leadership training for graduate students, enhancing communication education for undergraduate engineering students, developing evidence-based design project team formation strategies, and improving engineering design curricula.

\section{Dr. Mattox Beckman Jr, University of Illinois, Urbana-Champaign}

Mattox Beckman is a teaching assistant professor in the Computer Science department. He earned his doctorate from UIUC in 2003 under Sam Kamin, specializing in programming languages. He was a senior lecturer at the Illinois Institute of Technology for 12 years, and then returned to UIUC in 2015, where he teaches the Programming Languages and Data Structures courses. He has recently adopted Computer Science Education as his research focus.

\section{Mr. Lucas Anderson, University of Illinois, Urbana-Champaign}

Lucas Anderson is a Specialist in Education at the Center for Innovation in Teaching \& Learning (CITL) at the University of Illinois. He organizes the central campus teacher training program for the more than 800 new Teaching Assistants (TAs) Illinois welcomes each year. He continues to work with TAs throughout their graduate career by observing their classes, helping them collect and interpret feedback from their students, and shepherding them through CITL's teaching certificate program. He offers a variety of workshops every year to faculty, staff, TAs, and undergraduates, on topics including course design, running effective discussions, and using humor in the classroom. 


\title{
Integrated Engineering Leadership Initiative for Teaching Excellence (iELITE) Year Two: Assessment of Intermediate-Term Outcome for Graduate Teaching Assistant Training
}

\begin{abstract}
Since the spring of 2017, the Integrated Engineering Leadership Initiative for Teaching Excellence (iELITE) team has been developing and offering a course that seeks to train graduate teaching assistants (GTAs) in the College of Engineering at the University of Illinois at Urbana-Champaign. The training is to be applicable to all types of GTA contexts: lab, discussion, and lecture. Because many of our engineering students' career goals are within non-academic settings, students often have little natural motivation to develop effective pedagogical skills. As explained in our previous paper $^{1}$, the team made a strategic decision to combine the teaching of leadership skills and pedagogical skills in order to appeal to GTAs who plan to go into non-academic careers. In this paper, we will present our logic model for the iELITE program, which has four categories of inputs: GTAs, Engineering Faculty, Administration (College and Departments), and External Partners (industry sponsors). The logic model will lay out corresponding short-term, intermediate-term and long-term outcomes for each of the categories. The External Partners category is a new addition to the program this year. After collecting feedback from the teaching community in the college, we think that it is crucial to connect our content to what is being done in the professional workplace to make the learning experience more realistic. Intermediate-term outcomes in the GTAs category will be our main focus for the moment. Furthermore, we will discuss faculty feedback from those who have worked with past GTA participants in the program.
\end{abstract}

\section{Introduction}

In previous work, we described in detail the creation of an integrated teaching and leadership course for new Graduate Teaching Assistants (GTAs) in the College of Engineering at the University of Illinois at Urbana-Champaign. ${ }^{1}$ In summary, to provide value to GTAs with future careers in either academia or industry, we designed a course that provides pedagogical instruction for GTAs while highlighting how pedagogical skills can transfer to their future leadership roles. The course 


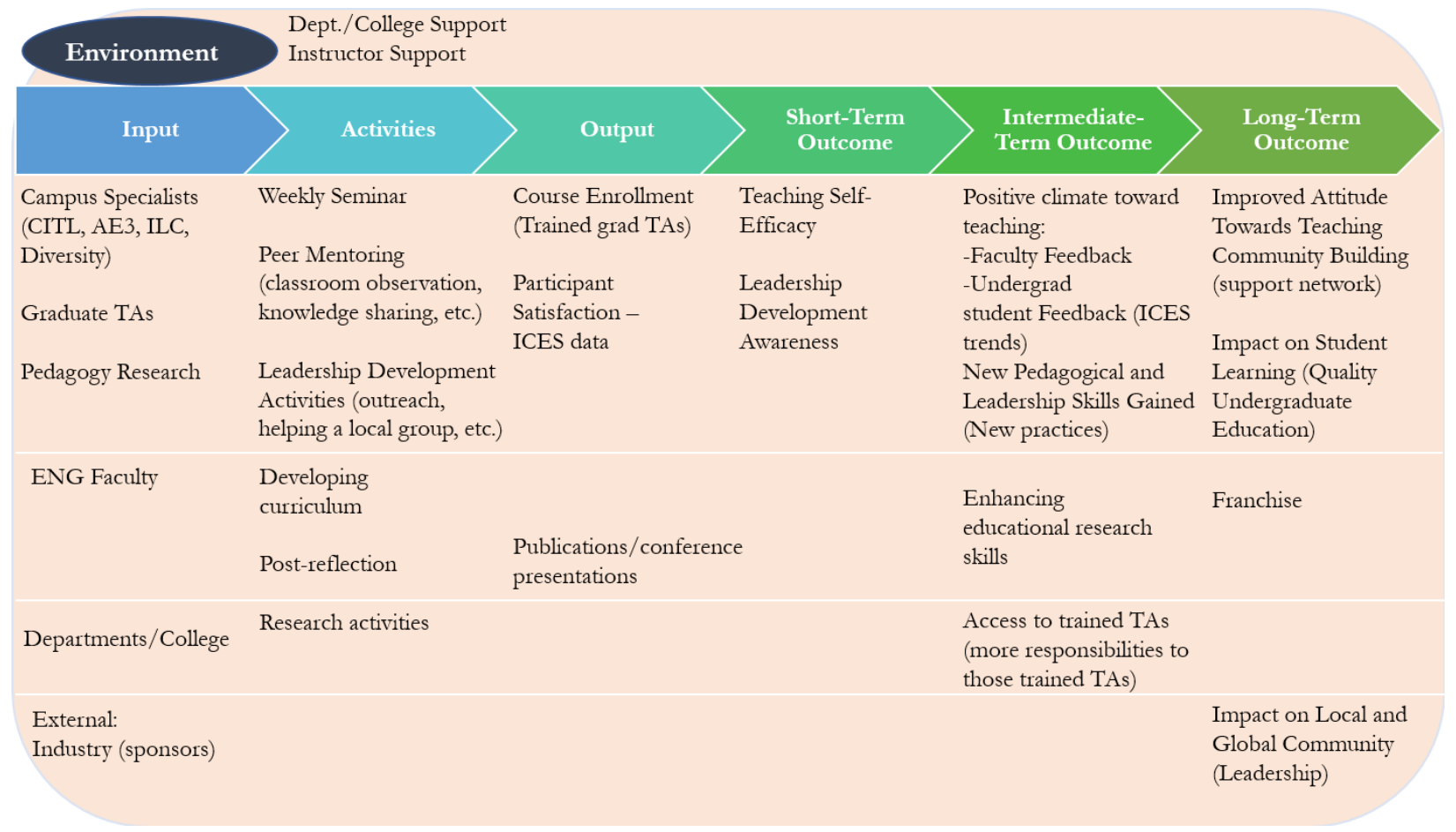

Figure 1: The iELITE Teaching and Leadership course Logic Model.

used an integrative approach where teaching and leadership topics were presented as mutually reinforcing. The original goals of the course were to improve teaching confidence and effectiveness, as well as increase each GTA's understanding of the connection between teaching and leadership. Our initial course evaluations were done using before and after surveys ${ }^{2,3}$, and they showed that the course indeed increased GTAs' confidence in their teaching, but did not significantly increase their awareness of the connection between teaching and leadership, perhaps because many GTAs in the class already saw the connection when they started.

In this paper, we turn our attention to evaluating the intermediate-term goals of the course. We present a logic model of the course as well as feedback from faculty who have worked with GTAs who were participants in the course.

\section{Logic Model}

In response to a helpful suggestion that was received from a colleague after attending the 2018 ASEE Conference, we created a Logic Model of the course. The logic model ${ }^{4}$ for the GTA training course delineates the structure of the program from its input stakeholders and participants through the course activities, outputs, and target outcomes. Creating the logic model, even after the initial implementation of the course, has proven useful to clarify understanding about how the program operates and what the results are that we hope to achieve.

Our previous work noted the collaboration between College of Engineering Faculty and various 
campus specialists, as well as the partnerships with several departments within the College of Engineering. In that work, we also explained the integration between teaching and leadership we demonstrated to GTAs. However, we had not yet synthesized those different threads into an overarching model of our program. Our development of the logic model shown in Figure 1 represents an important step forward in the development of the course. Though we had identified and measured specific outcomes of the course in our previous work, the logic model helped us identify additional outcomes and categorize them in terms of time (short-, intermediate-, or long-term) and in terms of matching them to different stakeholders (outcomes for the GTAs, outcomes for the faculty, etc.). While many of the inputs, activities, and short-term outcomes shown in the logic model were addressed in our previous work, the framework provided by the logic model aids us to investigate them in a linear way, and to move on to the identification and measurement of longer-term goals. We will proceed to address the features of the logic model one-by-one.

\section{Inputs}

The target outcomes of the course are not simple goals to achieve. In a large engineering college, there are GTAs from many different departments. Each department has an academic subculture and unique degree requirements that affect GTA motivation, or lack of motivation, to excel in their teaching role. The instructional inputs for such a broad training program must not be assembled in a naïve, ad hoc manner. Therefore, the inputs to the logic model include many campus specialists, as opposed to simply a team of motivated engineering faculty members. Specialists from the University's teaching and learning center, the College of Engineering's teaching academy, and the University's leadership center all have been invited to work as consultants on this program, including advising the core engineering faculty team and assisting with the course by teaching content in their areas of expertise. Graduate course aides assist with the course through sharing of the graduate student perspective with the instructional team, grading written assignments, and helping to advise student projects. The college supports the program by funding the instructional team on a service-in-excess line, as well as funding the program evaluation through the University's teaching and learning center. Individual departments support the program through in-kind hourly or teaching assistant support, as well as by providing students who take the course as part of their graduation, professional development, and/or teaching requirements. Finally, external industry sponsors offer additional, sustainable financial support as well as some industry-perspective instruction in return for the opportunity to recruit from a pool of graduate students.

\section{Activities}

The course consists of a weekly seminar that can be taken for one or two credit hours. Seminars are taught in an active-learning style, with plentiful group discussions and in-class activities such as think-pair-share. Some seminars are supplemented by reflective writing assignments. Students who take the course for two credits also complete a research project and present their findings in a poster session. Course instructors and course aides provide mentoring to these students as they work on their projects. Projects may also include outreach activities as needed to generate requisite data. 


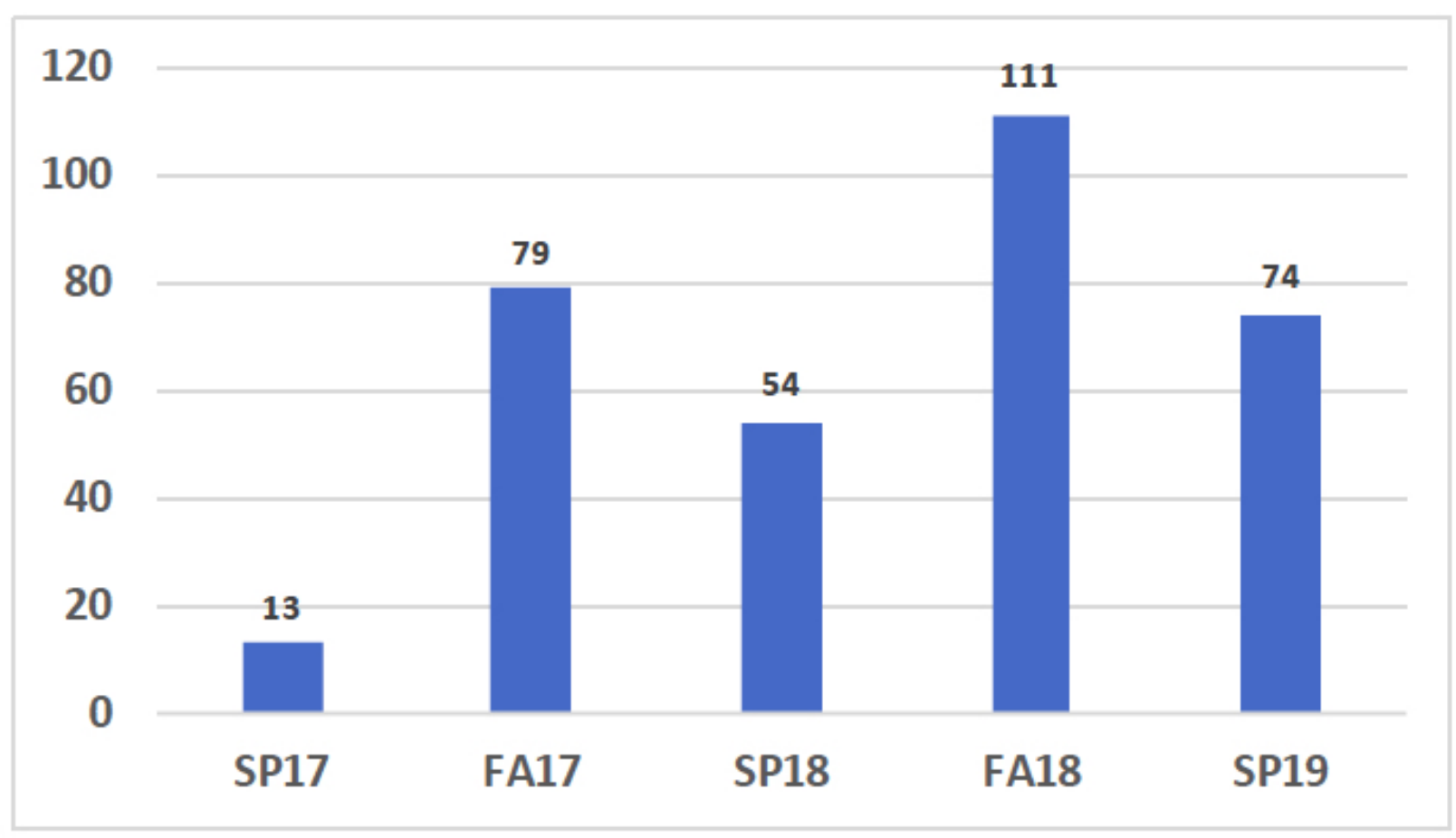

Figure 2: Course Enrollment

The instructional team meets weekly to develop the curriculum. Meeting activities include postreflections of each seminar, and planning outreach to potential supporters from across the campus, government, and industry.

\section{Outputs}

The primary output of the program are GTAs who have undergone additional training activities over the duration of an entire semester. Since the program piloted in the spring of 2017, enrollment has growth rapidly, as shown in Figure 2. In addition to the benefits that they gain through direct instruction and reflection, GTAs also benefit from the interactions with their peers, which combine to help them develop professional connections and, potentially, formation of communities of practice among themselves. To facilitate development of such communities of practice, GTAs are encouraged to sit in groups arranged according to the nature of their instructional duties-i.e. all Lab GTAs sit in one area of the room, all Project Course GTAs sit in another area, etc.- - such that all participants share similar teaching contexts.

The other two outputs of the program are: 1) increased GTA satisfaction with their own teaching effectiveness, which may be measurable through improved undergraduate student evaluations, and 2) publications and conference presentations by the instructional team for the benefit of the broader engineering education community. 


\section{Outcomes}

Program Outcomes are classified according to short-, intermediate-, and long-term targets. In the short-term, the individual participants should develop increased self-efficacy about their teaching, as well as an awareness of how their leadership skills can be enhanced through effective teaching.

In the intermediate-term, our goal is to improve trends in undergraduate student feedback and faculty satisfaction with GTA performance. An accompanying goal is that GTAs on the campus will exhibit new and improved pedagogical and leadership skills. The instructional team hopes to demonstrate enhanced educational research skills while the college as a whole benefits from access to GTAs who can accept greater responsibilities as a result of their training.

In the long-term, a culture shift toward improved attitudes about teaching is a primary outcome, featuring a strong and supportive community of motivated and skillful GTAs. Such a culture shift will increase the quality of undergraduate education in our college. As the instructional content is refined through many iterations of the program, the instructional team will consider development of a franchise model in order to bring these successful advances to other colleges and universities. Eventually, the program may result in increased effectiveness of engineers as global and local leaders as these skills become deeply ingrained throughout the profession.

Developing the logic model allowed us to distinguish between our short-, intermediate-, and longterm outcomes, and let us recognize that our previous assessments of our course had focused on short-term outcomes. We have begun to expand our assessment to include intermediate-term outcomes, and our early attempts at such assessments are described in what follows.

\section{Faculty Interview}

To assess the intermediate-term goal of faculty satisfaction with the performance of GTAs, we conducted two in-depth interviews ${ }^{5}$ with a faculty member and a GTA supervisor in two different departments that require new GTAs to undergo the training program. As suggested by a similar program $^{6}$ in assessing effectiveness of teacher training, these interviews provided some insights into 1) the alignment of course topics with the needs of faculty/supervisors; 2) effectiveness of GTA training; and 3) perceived transferable skills from the classroom to the workplace.

The first interviewee is a faculty member in the Mechanical Science and Engineering Department, who had previously run a similar GTA training program for his courses. By collaborating with faculty from the Education Department, he had created a course for GTAs who teach in sophomore level Mechanical Engineering classes. On average, 15 GTAs were enrolled each semester. The program was discontinued after a few years due to the heavy workload taken on by faculty who were teaching these courses. The second interviewee is a GTA supervisor in the Computer Science Department, who is affiliated with the English Department. He had undergone two semesters of training in his previous position as a GTA for a required undergraduate English course.

To understand the alignment of our course topics with the needs of the faculty and GTA supervisor, 
we started the interview by asking what challenges they face when managing GTAs. The two interviewees expressed different opinions. The engineering faculty member shared that the biggest challenge he faced came from getting new GTAs up to speed on their day-to-day tasks, which include facilitating active learning activities in the classroom. He preferred to have new GTAs who know the course content and understand the basics of how learning works. Furthermore, he greatly appreciates those GTAs who care about doing a good job and are able to help students learn. The GTA supervisor whose field of study is not in engineering shared a slightly different point of view. He indicated that the most challenging task is holding GTAs accountable for their job responsibilities. He also expressed the need to have GTAs go through basic pedagogical training and learn to properly interact with students. Not surprisingly, both the faculty member and GTA supervisor voiced concerns about GTAs who are not motivated to do their job. By comparing the feedback from the faculty member and GTA supervisor with our current course syllabus shown in Appendix A, we found that the combination of pedagogical and leadership topics aligns well with their needs.

The second part of the interview is targeted to evaluate the effectiveness of the GTA training program. With a list of past participants in the course, we asked the interviewees to identify the GTAs they worked with and rate each one's job performance using a scale of 1 to 5 (poor, below average, average, good, excellent). The faculty member had worked with nine GTAs on the list: four GTAs received a rating of excellent, three GTAs received a rating of good, and two GTAs received a rating of average. The faculty member elaborated that those rated as excellent and good are GTAs who have made significant contributions to the course, and those rated as average did what is required only. The GTA supervisor has worked with five GTAs on the list: one GTA was rated as excellent, two GTAs were rated as good, one was rated as average and one was rated as below average. The GTA supervisor uses a different rubric in his rating: those rated as excellent and good are GTAs who are very responsive to ad hoc duties and go above and beyond in helping students, whereas those rated as average did the bare minimum and those rated as below average were slow to respond to emails and generally difficult to reach when needed.

In the last part of the interview, we asked the faculty member and GTA supervisor whether the skills necessary for being a GTA are transferable to the workplace, and if so what specific skills are most transferable. Both the faculty member and GTA supervisor identified communication as the skill that would be needed in the workplace regardless of one's career path. Other skills mentioned include classroom presence (for academic careers), handling difficult situations, and working with a diverse audience.

By using thematic coding ${ }^{7}$ to analyze the responses from the two interviews, we found that motivation of the GTAs is an area of concern for both the faculty member and GTA supervisor. Furthermore, both interviewees think that communication skill is essential for teaching and future career in the professional workplace.

Based on the results of these early interviews, we believe our course topics are well-aligned with what faculty and course supervisors want GTAs to learn in the realm of teaching and leadership. We plan to conduct additional in-depth interviews with more faculty members and GTA supervisors to verify this finding. Furthermore, we would like to compare the job performance ratings of GTAs who have gone through our program with GTAs who have not. 


\section{Undergraduate Student Feedback}

It stands to reason that having well-trained GTAs should result in more effective instruction for the undergraduates in the classroom. Our logic model thus identifies improved undergraduate feedback on GTA performance as an intermediate-term outcome. To measure this outcome, we first hoped to look at the end of semester student course evaluations for GTAs. Combining these evaluations with data about which courses our GTAs served, we hope to see improvements in the evaluation scores of GTAs who attended our class.

Unfortunately, getting access to student course evaluation data has proved to be difficult due to varying policies among departments at the College of Engineering. We are considering alternative approaches to gathering undergraduate student feedback, such as interviewing individual students who have taken courses taught by our GTAs, and by interviewing the GTAs themselves a year or so after they have completed our class.

\section{Conclusion}

We have developed a logic model for our integrated teaching and leadership course for Engineering GTAs, which has allowed us to better understand the inputs, activities, outputs, and outcomes of our course. Having already developed materials to address short-term outcomes of teaching self-efficacy and leadership awareness, we have begun to assess our intermediate-term outcomes. Interviews with faculty have revealed a range of perspectives about what is most needed in newly trained GTAs and how well teaching skills contribute to leadership skills. We are continuing to survey our GTAs and faculty who work with them to understand what effect our training has and how we can modify or improve our material to be able to address the needs of different departments and GTA areas of responsibility. 


\section{Appendix A Course Topics}

\begin{tabular}{|c|c|}
\hline Week & Topic \\
\hline 1 & $\begin{array}{l}\text { Introduction - Opportunities \& Challenges of being a TA } \\
\text { The course staff will present the syllabus and then divide the GTAs into four groups based on their teaching duties. Small group discussion } \\
\text { will then delve into challenges GTAs would face in their teaching assignment and opportunities that come with it. }\end{array}$ \\
\hline 2 & $\begin{array}{l}\text { Interacting with Students } \\
\text { An instructor will present pit-falls and best practices for interacting with students through email and office hours. This topic is closely } \\
\text { related to the workplace, in which engineers are expected to demonstrate professionalism. }\end{array}$ \\
\hline 3 & $\begin{array}{l}\text { Bloom's Taxonomy Overview } \\
\text { An instructor will introduce Bloom's Taxonomy and engage students in small group discussion of how to apply it in defining learning } \\
\text { objectives and writing homework and exam questions. }\end{array}$ \\
\hline 4 & $\begin{array}{l}\text { Active Learning } \\
\text { A campus specialist will present the benefits of utilizing active learning techniques in the classroom and potential challenges during } \\
\text { implementation and deployment. GTAs will be engaged in several active learning activities throughout the session and they will be asked to } \\
\text { reflect on their experience at the end. }\end{array}$ \\
\hline 5 & $\begin{array}{l}\text { Academic Integrity } \\
\text { A dean from the college will present the resources available to GTAs in terms of handling academic integrity cases and the reason why we } \\
\text { have such policy at the university. Several cases will be presented to bring out discussion of Dos and Don'ts when handling academic } \\
\text { integrity violations. }\end{array}$ \\
\hline 6 & $\begin{array}{l}\text { Leadership Part } 1 \text { - Clifton Strengths } \\
\text { A campus specialist from the leadership center will explain the themes from Clifton Strengths and help GTAs to make sense of their } \\
\text { individual Clifton Strengths report. Group activities will be carried out to show a diverse strength profile within the class and how each GTA } \\
\text { can leverage his or her strengths to achieve success professionally. }\end{array}$ \\
\hline 7 & $\begin{array}{l}\text { Informal Early Feedback } \\
\text { An instructor will present the essentials of mid-semester teaching evaluation and how it applies to the workplace. Small group discussions } \\
\text { will be carried out to encourage GTAs to explore aspects of evaluation that can help improve their teaching before the semester ends. }\end{array}$ \\
\hline 8 & $\begin{array}{l}\text { General Rubric Design } \\
\text { A campus specialist will present how to design a rubric and how it can help GTAs grade assignments and assessments fairly and efficiently. } \\
\text { The tie to performance evaluation in the professional workplace will be emphasized. }\end{array}$ \\
\hline 9 & $\begin{array}{l}\text { Applied Rubrics } \\
\text { An instructor will present specific grading scenarios related to the GTAs' field of study. Group activities will be carried out to analyze a few } \\
\text { work examples from students, which highlight the importance of using a rubric. }\end{array}$ \\
\hline 10 & $\begin{array}{l}\text { Project Management } \\
\text { A faculty guest speaker will present on controlling the critical path of project management and how project management concepts can be } \\
\text { applied to both personal and professional space. An open critique of the presentation as a teaching example will take place at the end to } \\
\text { show elements that goes into planning of a lesson. }\end{array}$ \\
\hline 11 & $\begin{array}{l}\text { Diversity and Inclusion } \\
\text { An instructor or a campus specialist will present on the importance of diversity in engineering and how to create an inclusive space in the } \\
\text { classroom. Examples of diverse workforce / team will be brought up throughout the session. }\end{array}$ \\
\hline 12 & $\begin{array}{l}\text { Leadership Part } 2 \text { - Industry Sponsors } \\
\text { An industry professional will present on leadership skills needed in the workplace to succeed professionally. This session can vary slightly } \\
\text { based on personal experience of the industry professional. }\end{array}$ \\
\hline 13 & $\begin{array}{l}\text { Student Motivation } \\
\text { A campus specialist will present the motivation theory of value and expectancy. Examples of different values and expectancies will be } \\
\text { outlined and explained, each with a brief discussion of scenarios that GTAs have experienced themselves. }\end{array}$ \\
\hline 14 & $\begin{array}{l}\text { Wrap-up \& Poster Presentation } \\
\text { An instructor will recap the semester and highlight the main ideas presented throughout the course. A poster presentation will be held at } \\
\text { the end to showcase the work done by GTAs who are enrolled in the two-credit hour option of the course. }\end{array}$ \\
\hline
\end{tabular}

\section{References}

[1] Hyun Hannah Choi, Yuting W. Chen, A. Mattox Beckman Jr., Lucas Anderson, Blake Everett Johnson, Matthew D. Goodman, and Nicole Johnson-Glauch. Integrative Engineering Lead- 
ership Initiative for Teaching Excellence ( iELITE ). In ASEE Annual Conference, Salt Lake City, Utah, USA, 2018. ASEE.

[2] Sue Ellen DeChenne, Larry G. Enochs, and Mark Needham. Science, Technology, Engineering, and Mathematics Graduate Teaching Assistants Teaching Self-Efficacy. Journal of the Scholarship of Teaching and Learning, 12(4):102-123, 2012. ISSN 1527-9316. URL http://josotl.indiana.edu/article/view/2131.

[3] E. Alpay and E. Walsh. A Skills Perception Inventory for Evaluation Postgraduate Transferable Skills Development. Assessment and Evaluation in Higher Education, 33(6):581-598, 2008.

[4] Lisa Wyatt. Knowlton and Cynthia C. Phillips. The Logic Model Guidebook: Better Strategies for Great Results. SAGE, 2013. ISBN 9781452216751.

[5] Greg Guest, Emily E. Namey, and Marilyn L. Mitchell. Collecting Qualitative Data: A Field Manual for Applied Research. SAGE Publications, Ltd, 1 Oliver's Yard, 55 City Road London EC1Y 1SP, $2013 . \quad$ ISBN 9781-4129-8684-7 978-1-5063-7468-0. doi: 10.4135/9781506374680. URL http://methods.sagepub.com/book/collecting-qualitative-data/.

[6] Sheila C. Palmer and Pamela M. Norris. Effectiveness Of The Woodruff School Doctoral Teaching Intern Program. pages 1.176.1-1.176.9, Washington, District of Columbia, June 1996. URL https: //peer. asee.org/6007.

[7] Richard E. Boyatzis. Transforming Qualitative Information: Thematic Analysis and Code Development. SAGE, April 1998. ISBN 978-0-7619-0961-3. Google-Books-ID: rfClWRhIKAC. 